\title{
Dolinas em arenitos da Bacia do Paraná: evidências de carste subjacente em Jardim (MS) e Ponta Grossa (PR)
}

\author{
William Sallun Filho ${ }^{1}$ \& Ivo Karmann ${ }^{2}$
}

\begin{abstract}
Resumo Dolinas em arenitos ocorrem na Formação Aquidauana em Jardim (MS) e na Formação Furnas em Ponta Grossa (PR), Bacia do Paraná. Na região Ponta Grossa o recuo das rochas areníticas é marcado pela "Escarpa da Formação Furnas", enquanto em Jardim não há escarpa associada. As dolinas de Jardim são geralmente amplas e rasas, e as de Ponta Grossa profundas e escarpadas. Em Ponta Grossa as dolinas, tiveram sua origem vinculada, na maioria dos estudos, à erosão subterrânea nos arenitos, devido à presença de feições de relevo ruiniforme, proximidade de escarpas e ausência equivocada de rochas carbonáticas no embasamento da bacia. As dolinas de Jardim e Ponta Grossa são fenômenos de colapso geradas por processo de piping, ocasionado pelo desenvolvimento de um sistema cárstico subjacente, profundo, em ambiente freático, nas rochas carbonáticas do embasamento. O papel do carste subjacente na formação de dolinas em arenito é demonstrado por: 1) as dolinas não estão distribuídas ao longo de todas as unidades areníticas da Bacia do Paraná, mas pelo contrário, são restritas apenas em localidades com rochas carbonáticas no embasamento da bacia; 2) feições de relevo ruiniforme são formas superficiais de origem erosiva ou intempérica nos arenitos e podem ser atribuídas a pseudocarste, não tendo relação direta com as dolinas, que mesmo estando na superfície, representam pontos de injeção de água meteórica, conectado em profundidade ao sistema cárstico; 3) o alinhamento de feições de superfície, além de demonstrar o controle estrutural nos arenitos, expressa direção de condutos cársticos em profundidade. A "Depressão de Vila Velha", descrita pela primeira vez neste estudo, abrange todas as dolinas da região de Ponta Grossa, é reflexo do processo de piping devido ao carste subjacente. Na área de carste exposto feições típicas não são muito freqüentes ou evidentes, devido à composição dolomítica, e as dolinas, são mais evidentes nos arenitos do que nos próprios carbonatos. Porém, em Jardim, a transição geomorfológica gradual entre arenitos e carbonatos torna mais visível o carste subjacente, expondo as feições cársticas, diferentemente da região de Ponta Grossa onde o carste encontra-se distante das dolinas e em maior profundidade.
\end{abstract}

Palavras-chave: dolina, arenito, carste subjacente, pseudocarste, Formação Furnas, Formação Aquidauana.

\begin{abstract}
Dolines in Paraná Basin sandstones: evidence of subjacent karst conditions in Jardim $(M S)$ and Ponta Grossa (PR) In the Paraná Basin, dolines in sandstones occur in the Aquidauana Formation in Jardim (MS) and in the Furnas Formation in Ponta Grossa (PR). In the Ponta Grossa region, the retreat of arenitic rocks is marked by the "Furnas Formation Escarpment", whereas in Jardim there is no associated escarpment. The dolines of the Jardim are generally extensive and shallow, and those of the Ponta Grossa deep and scarped. In Ponta Grossa, the dolines have had their origin associated, in most studies, with the subsurface erosion of sandstones, due to the presence of ruiniform relief features, the proximity of escarpments and the mistaken absence of carbonatic rocks in the basement of the basin. The Jardim and Ponta Grossa dolines are collapse phenomena generated by a piping process, brought about by the development of a subjacent karst system, at depth, in a phreatic environment, in the carbonatic basement rocks. The role of subjacent karst in doline formation in sandstones is demonstrated by: 1) rather than being distributed along all the arenitic units of the Paraná Basin, dolines are restricted to only those locations with carbonatic rocks in the basement structures of the basin; 2) ruiniform relief features are surface structures originating from erosive or weathering processes in sandstones and can be attributed to pseudokarst, having no direct relationship with the dolines, which even when present at the surface, represent points of injection of meteoric water, connected at depth to the karst system; 3) besides being evidence of structural control in the sandstones, the alignment of surface features shows the direction of karst conduits at depth. The "Vila Velha Depression", described for the first time in this study, which includes the dolines in the Ponta Grossa region, is a reflection of the piping process brought about by the subjacent karst. In the exposed karst area typical features are not very frequent or evident, due to dolomitic composition, and the dolines are more evident in sandstones than the actual carbonate rocks. However, in Jardim, the gradual geomorphological transition between sandstones and carbonate rocks makes the subjacent karst more visible, which exposed the karst features, in a different manner to the Ponta Grossa region, where the karst is encountered at a distance from the dolines and at greater depth.
\end{abstract}

Keywords: doline, sandstone, subjacent karst, pseudokarst, Furnas Formation, Aquidauana Formation.

1 - Instituto Geológico, Secret. do Meio Ambiente do Estado de São Paulo, São Paulo, SP, Brasil. E-mail: wsallun@igeologico.sp.gov.br

2 - Instituto de Geociências, Universidade de São Paulo, São Paulo, SP, Brasil. E-mail: ikarmann@usp.br 
INTRODUÇÃO Notáveis exemplos de dolinas ocorrem em arenitos da Bacia do Paraná, na Formação Aquidauana em Jardim (MS) na Serra da Bodoquena (Lino et al. 1984, Sallun Filho et al. 2004, Sallun Filho 2005 - Fig. 1) e na Formação Furnas na região de Ponta Grossa (PR - Maack 1946; Melo et al. 2000, Melo 2002) e Nova Campina (SP - Santoro \& Frascá 1989; Hiruma et al. 2007).

As formações Furnas e Aquidauana são unidades compostas essencialmente por arenitos. A Formação Furnas, que alcança até $300 \mathrm{~m}$ de espessura na região, é uma unidade composta de arenitos quartzosos, de granulação média a grossa, feldspáticos e/ou caulínicos, mal selecionados, com estratificação cruzada, intercalados com níveis delgados de conglomerados (Assine 1999). A Formação Aquidauana, com até 500 $\mathrm{m}$ de espessura na região, é composta essencialmente de arenitos quartzosos, finos a grossos, com estratificação plano-paralela incipiente, níveis de lamitos e conglomerados subordinados (Araújo et al. 1982).

Este trabalho apresenta novos dados sobre dolinas em arenitos da Bacia do Paraná, com o objetivo de demonstrar sua relação com o carste subjacente em rochas carbonáticas do embasamento. Entende-se aqui como carste subjacente aquele que se desenvolve em profundidade através da dissolução de rochas solúveis cobertas por rochas resistentes e insolúveis (Jackson \& Bates 1997, Culver \& White 2005), as quais podem sofrer colapsos e subsidência (com formação de dolinas) devido à carstificação em profundidade. Segundo Klimchouk \& Ford (2000a) o carste subjacente é um tipo de carste interestratal. Dolinas apesar de serem feições superficiais, possuem origem vinculada à existência de

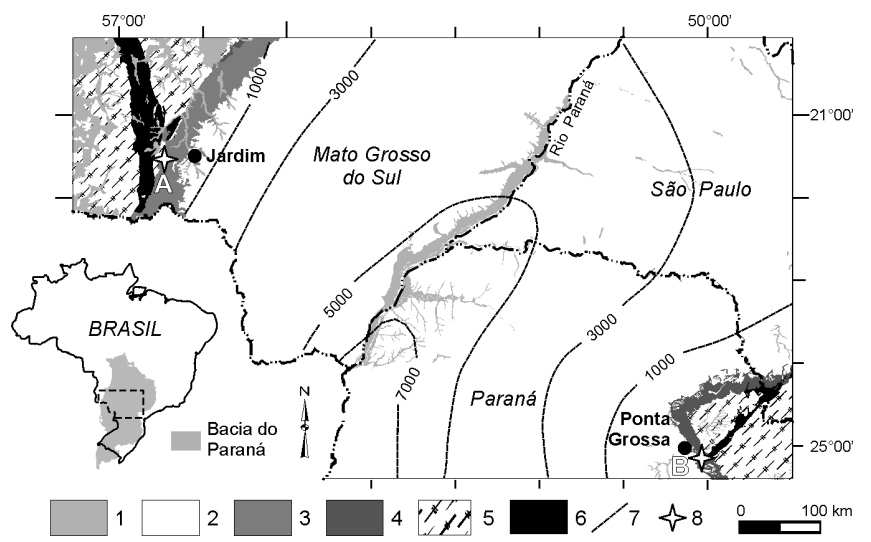

Figura 1 - Mapa de localização das dolinas em arenitos nas respectivas unidades da Bacia do Paraná. 1- Depósitos quaternários; Bacia do Paraná: 2- Unidades indivisas, 3- Formação Aquidauana, 4- Formação Furnas; Embasamento Pré-cambriano: 5- Rochas não carbonáticas, 6- Rochas carbonáticas dos grupos Corumbá $(M S)$ e Itaiacoca (SP e PR); 7- Isópacas (m) da Bacia do Paraná; 8- Ocorrências de dolinas: A-Jardim (MS), B-Ponta Grossa (PR - modificado de Bizzi et al. 2001, e Milani \& Ramos 1998). condutos desenvolvidos em subsuperfície.

Diversas hipóteses foram formuladas para explicar a origem destas dolinas, especialmente na Formação Furnas. Uma destas hipóteses é a existência de processos cársticos em profundidade que geram colapsos em superfície (Maack 1946 e 1956, Le Bret 1962, Bigarella et al. 1994). Porém, como na Formação Furnas as dolinas se situam junto a feições de relevo ruiniforme (escarpas) da borda da Bacia do Paraná, com menor espessura de sedimentos (Figs. 1 e 2), alguns autores (Lima et al. 1975, Soares 1989, Melo et al. 2000, Melo 2002) supõem que foram geradas por erosão subterrânea nos arenitos da Formação Furnas, por carregamento de grãos (piping) por fluxo de água subterrânea no aqüífero em direção à escarpa, por vezes ignorando a presença de carbonatos subjacentes, ou mesmo colocando dúvida sobre sua existência. Porém, nas ocorrências de dolinas de Jardim (MS) a presença de carste subjacente é mais visível e já foi sugerida por Lino et al. (1984). Em Jardim as escarpas da Formação Aquidauana situam-se a centenas de quilômetros (Fig. 2) e há uma transição gradual geomorfológica entre arenitos e carbonatos, em vários estágios da evolução do sistema cárstico associado, diferentemente das ocorrências da região de Ponta Grossa onde o carste encontra-se distante das dolinas e em maior profundidade. Esses fatores discordantes entre as duas ocorrências necessitavam de um estudo mais aprofundado para diagnosticar qual o controle efetivo que origina feições tão singulares na Bacia do Paraná.

A premissa inicial da existência de um carste subjacente se baseia no fato de que, mesmo sendo feições relativamente abundantes, as dolinas não estão distribuídas ao longo de todas as unidades areníticas da Bacia do Paraná, independentemente da existência de escarpas associadas, mas pelo contrário, são restritas

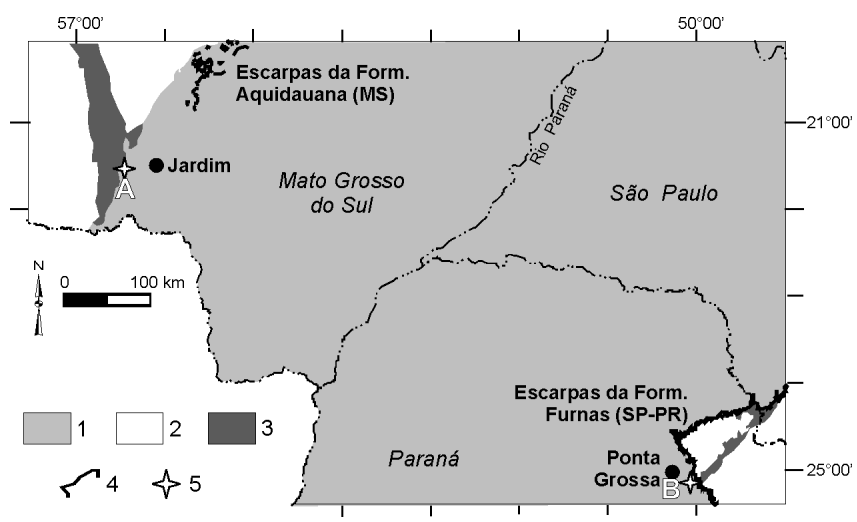

Figura 2 - Localização das dolinas em arenitos da Bacia do Paraná e escarpas das formações Aquidauana e Furnas. 1- Unidades indivisas da Bacia do Paraná; Embasamento Pré-cambriano: 2- Rochas não carbonáticas, 3-Rochas carbonáticas dos grupos Corumbá (MS) e Itaiacoca (SP e PR); 4- Escarpas; 5- Ocorrências de dolinas em arenitos: A-Jardim (MS), B-Ponta Grossa (PR). Escarpas modificadas de Beurlen (1956), Maack (1953) e Ponçano et al. (1981). 
a localidades onde ocorrem rochas carbonáticas como embasamento das unidades fanerozóicas. No caso da Formação Furnas (SP e PR), o embasamento é constituído de carbonatos do Grupo Itaiacoca, e, no caso da Formação Aquidauana (MS), por carbonatos dos grupos Cuiabá e Corumbá, ambos de idade proterozóica.

MATERIAIS E MÉTODOS Devido às diferentes formas de ocorrências das dolinas, foram empregadas técnicas distintas para o estudo das feições em Jardim (MS) e Ponta Grossa (PR).

Em Jardim foi realizado mapeamento litológico e geomorfológico para identificar diferentes compartimentos. A delimitação de feições foi feita a partir do Modelo Digital de Terreno (MDT), imagens de satélite (Landsat $7+\mathrm{ETM}$ ), fotografias aéreas em escala 1:60.000, identificação e mapeamento de campo. O MDT foi gerado a partir de dados do SRTM (2006). O mapeamento de dolinas em campo visou sua localização e caracterização quanto à forma em planta e em perfil, além das características geológicas, devido à pequena escala dos mapas topográficos e fotografias aéreas existentes. Em campo foi utilizado GPS com altímetro barométrico para localização e determinação da amplitude das dolinas.

Em Ponta Grossa (PR) foi utilizado MDT a partir do SRTM (2006), fotografias aéreas em escala 1:25.000 e dados bibliográficos para comparação com feições descritas em Jardim.

A rugosidade foi calculada, em escala 1:50.000, pela razão entre a área real e a área plana (Hobson 1972) a partir dos dados do SRTM (2006). Em ambos os casos, a orientação preferencial e os alinhamentos de feições cársticas, como dolinas, nascentes e caver- nas, foram traçados para correlação com condutos em profundidade. Os mapas de rugosidade e declividade foram gerados utilizando-se a extensão Surface Areas and Ratios from Elevation Grid, v. 1.2 (Jenness 2002) do Arcview 3.2, a partir de cada célula da malha ( $g r i d$ ) de $90 \mathrm{~m}$ do SRTM (2006).

A forma em perfil de dolinas (perfil suave ou íngreme) foi definida a partir da razão entre a profundidade e o diâmetro (P/D), para diferenciar dolinas, poljes, corredores e canyons (mais largas que fundas, com índice menor ou igual a 1) de chaminés, poços, abismos e fendas (mais fundas do que largas, com índice menor que 1 - White 1988). Quanto maior o valor de P/D mais íngreme é o perfil da dolina. Para dolinas assimétricas a razão P/D foi obtida utilizando o diâmetro médio calculado a partir dos eixos maior e menor. A localização de algumas cavernas e dolinas foram obtidas no Cadastro Nacional de Cavidades da Sociedade Brasileira de Espeleologia (SBE).

\section{DOLINAS NA FORMAÇÃO AQUIDAUANA EM}

JARDIM (MS) As dolinas em arenitos da Serra da Bodoquena (MS) ocorrem em uma superfície aplainada denominada Depressão do Rio Miranda (Alvarenga et al. 1982), constituída na região por rochas cristalinas do embasamento e sedimentares da Bacia do Paraná (Formação Aquidauana). Esta depressão compreende planícies cársticas com morros residuais e dolinas em rochas dolomíticas dos grupos Corumbá e Cuiabá (Fig. 3) e dolinas nos arenitos da Formação Aquidauana, bem como nas respectivas coberturas de solo. A Depressão do Rio Miranda, disposta em rampa suave entre as cotas topográficas de 200 a $400 \mathrm{~m}$, é recoberta pelos arenitos que, gradativamente, aumentam em espessura

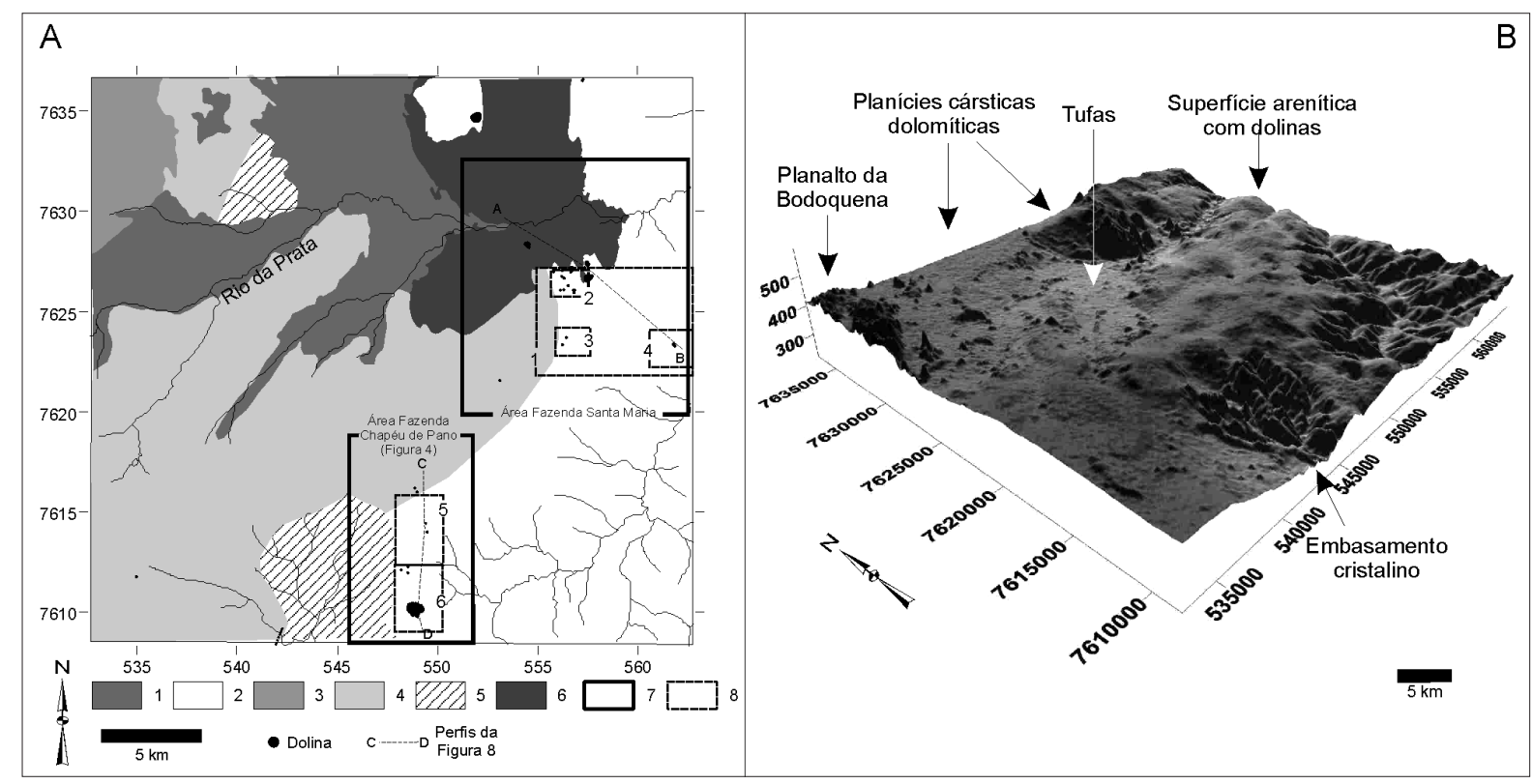

Figura 3 - Dolinas na Formação Aquidanana. A- Mapa geológico e de localização das dolinas. 1-Depósitos de tufas (Quaternário); 2- Formação Aquidauana; Grupo Corumbá: 3-Calcários, 4- Rochas siliciclásticas e dolomitos; Grupo Cuiabá: 5- Rochas siliciclásticas, 6- Mármores; 7-Áreas de detalhe; 8- Áreas utilizadas para o cálculo da rugosidade. B-Modelo Digital de Terreno (MDT) com os principais compartimentos morfológicos de Fig. $3 \mathrm{~A}$. 
para leste, em direção ao Planalto de Maracaju-Campo Grande. Nesta região a escarpa arenítica associada a Formação Aquidauana encontra-se bastante disseca$\mathrm{da}$, tendo recuado para leste com erosão remontante, e situando-se, atualmente, a mais de $100 \mathrm{~km}$ a nordeste da ocorrências de dolinas. As dolinas localizam-se em áreas muito planas com baixo nível de rugosidade, entre 1,0003 e 1,0005 para as áreas de detalhe (Fig. 3A). Isso ocorre devido a grande amplitude das depressões, que só podem ser visualizadas em escalas 1:50.000 ou maiores.

Foram localizadas 25 dolinas (Tab. 1), com diâmetros e profundidades muito variadas, em geral muito amplas com $200 \mathrm{~m}$ em média, atingindo no máximo $900 \mathrm{~m}$ de diâmetro e $75 \mathrm{~m}$ de profundidade. Dois tipos morfológicos de dolinas foram identificados nas duas áreas, distintos pela morfologia de depressões com vertentes suaves a abruptas, apresentando uma relação P/D entre 0,04 e 1,22 . A morfologia dominante corresponde a dolinas com uma relação P/D baixa (média de 0,23), vertentes de inclinação suave, fundo plano ou com a presença de lago. Dolinas com relação P/D maior são menos freqüentes, apresentando vertentes de alta inclinação, de fundo plano ou com a presença de lago. Depressões maiores são, por vezes, compostas de dolinas menores, tornando difícil a delimitação na escala utilizada, pois são muito amplas e suaves.

Como foi encontrada em campo uma quantidade muito grande de dolinas, optou-se pela definição de duas áreas de amostragem (Fig. 3A), na Fazenda Cha-

Tabela 1 - Dolinas da região de Jardim (MS - Sallun Filho 2005).

\begin{tabular}{|c|c|c|c|c|c|c|}
\hline Nome & $\begin{array}{l}\text { UTM E / N } \\
(\text { Zona } 21 \mathrm{~K})\end{array}$ & $\begin{array}{l}\text { Eixo } \\
\text { maior }\end{array}$ & $\begin{array}{c}\text { Dimensões } \\
\text { em planta }(\mathrm{m})\end{array}$ & $\begin{array}{l}\text { Prof. } \\
(\mathrm{m})^{*}\end{array}$ & Litol. $* *$ & $\mathrm{P} / \mathrm{D}$ \\
\hline Pt.27 & $\begin{array}{c}556292 \\
7626638 \\
\end{array}$ & NS & $30 \times 20$ & 6 & Solo & 0,24 \\
\hline Pt.28 & $\begin{array}{c}556192 \\
7627017\end{array}$ & N70E & $190 \times 80$ & 20 & Solo e Dol. & 0,16 \\
\hline Pt.29 & $\begin{array}{c}555764 \\
7626950\end{array}$ & ------- & $18 \times 16$ & 2 & Solo & 0,12 \\
\hline Pt.30 & $\begin{array}{c}556164 \\
7626732\end{array}$ & N10E & $50 \times 45$ & 15 & Solo & 0,32 \\
\hline Pt.68 & $\begin{array}{c}553075 \\
7621516\end{array}$ & -------- & $\sim 600 \times 500$ & 50 & Solo & 0,09 \\
\hline Pt.101 & $\begin{array}{c}556495 \\
7626268 \\
\end{array}$ & -------- & $\sim 160 \times 100$ & $\sim 5$ & Solo & 0,04 \\
\hline Pt.102 & $\begin{array}{c}556273 \\
7626061\end{array}$ & -------- & $\sim 150 \times 90$ & $\sim 5$ & Solo e Dol. & 0,04 \\
\hline Pt.103 & $\begin{array}{c}556104 \\
7626042 \\
\end{array}$ & $\mathrm{~N} 76 \mathrm{E}$ & $\sim 30 \times 20$ & 30 & Solo e Dol. & 1,22 \\
\hline Pt.104 & $\begin{array}{c}556779 \\
7625910\end{array}$ & N40W & 50 & 2 & Solo & 0,04 \\
\hline Pt.105 & $\begin{array}{c}556762 \\
7626048\end{array}$ & N05W & 15 & 6 & Solo & 0,4 \\
\hline Pt.106 & $\begin{array}{c}556813 \\
7626056\end{array}$ & -------- & 8 & 0,5 & Solo & 0,05 \\
\hline Pt.107 & $\begin{array}{c}557429 \\
7626563 \\
\end{array}$ & $\mathrm{~N} 40 \mathrm{E}$ & $\sim 300 \times 250$ & $\sim 20$ & Solo e Dol. & 0,07 \\
\hline Pt.108 & $\begin{array}{c}557428 \\
7627334 \\
\end{array}$ & -------- & $\sim 250 \times 150$ & $\sim 20$ & Solo & 0,1 \\
\hline Pt.109 & $\begin{array}{c}556405 \\
7623671 \\
\end{array}$ & -------- & $\sim 300$ & $\sim 20$ & Solo & 0,07 \\
\hline Pt.120 (Lagoa Vermelha) & $\begin{array}{c}549043 \\
7610013 \\
\end{array}$ & ------- & $\sim 900 \times 800$ & $\sim 50$ & Aren. & 0,06 \\
\hline Pt.121 & $\begin{array}{c}548470 \\
7611907\end{array}$ & -------- & $\sim 300$ & ----- & $\begin{array}{c}\text { Solo } \\
\text { arenoso }\end{array}$ & ----- \\
\hline Pt.122 & $\begin{array}{c}548487 \\
7612210 \\
\end{array}$ & -------- & $\sim 300$ & ----- & $\begin{array}{c}\text { Solo } \\
\text { arenoso }\end{array}$ & ----- \\
\hline Pt.123 & $\begin{array}{c}548139 \\
7612050\end{array}$ & -------- & $\sim 300$ & ----- & $\begin{array}{c}\text { Solo } \\
\text { arenoso }\end{array}$ & ---- \\
\hline Pt.124 & $\begin{array}{l}549438 \\
7613947\end{array}$ & -------- & 100 & ----- & $\begin{array}{l}\text { Solo } \\
\text { arenoso }\end{array}$ & ---- \\
\hline Pt.125 & $\begin{array}{c}549368 \\
7614373\end{array}$ & N20W & ------- & ----- & $\begin{array}{c}\text { Solo } \\
\text { arenoso }\end{array}$ & ----- \\
\hline Pt. 126 & $\begin{array}{c}548937 \\
7615944\end{array}$ & -------- & ------- & ----- & $\begin{array}{c}\text { Solo } \\
\text { arenoso }\end{array}$ & ------ \\
\hline Pt.127 & $\begin{array}{c}548825 \\
7616146 \\
\end{array}$ & N10W & -------- & ----- & $\begin{array}{c}\text { Solo } \\
\text { arenoso }\end{array}$ & ------ \\
\hline Pt.128 & $\begin{array}{c}556200 \\
7623305\end{array}$ & -------- & -------- & ----- & Solo & ----- \\
\hline $\begin{array}{l}\text { Pt.26 (Lagoa Misteriosa, } \\
n^{\circ} \text { SBE MS-43) }\end{array}$ & $\begin{array}{c}556748 \\
7627057\end{array}$ & $\mathrm{~N} 35 \mathrm{E}$ & $\sim 400 \times 200$ & $\begin{array}{c}75 \\
(+220 \mathrm{sub} .)\end{array}$ & Dol. e Aren. & 0,27 \\
\hline $\begin{array}{l}\text { Buraco das Araras }\left(n^{\circ}\right. \\
\text { SBE MS-11) }\end{array}$ & $\begin{array}{c}561834 \\
7623338 \\
\end{array}$ & N50W & $125 \times 70$ & 60 & Aren. & 0,64 \\
\hline
\end{tabular}

*sub.: subaquático; **Dol.: Dolomito (grupos Corumbá e Cuiabá), Aren.: Arenito (Fm. Aquidauana). 
péu de Pano e Fazenda Santa Maria (conhecido também como "Passo do Curê"), pois o mapeamento de todas as dolinas em campo é praticamente impossível.

Área da Fazenda Chapéu de Pano $\mathrm{Na}$ área da Fazenda Chapéu de Pano não ocorre transição geomorfológica entre as faixas de afloramentos de arenitos e dolomitos. A rugosidade de 1,0005 obtida neste setor (área 6, Fig. 3A) é um pouco maior do que para a área como um todo. Nesta área as dolinas são muito amplas e suaves, desenvolvidas em solo arenoso ou arenito Aquidauana (Fig. 4), sem dolomitos expostos. O melhor exemplo deste tipo é a dolina da "Lagoa Vermelha", na Fazenda Chapéu de Pano (Ponto 120), desenvolvida no arenito, de forma ampla e rasa $(\mathrm{P} / \mathrm{D}=0,06)$, com cerca de 900 x $800 \mathrm{~m}$ de eixo maior e menor, por $50 \mathrm{~m}$ de profundidade (Fig. 4). Os alinhamentos de dolinas neste setor são N15W e N60E e as dolinas elípticas possuem direções de eixo maior entre N10W e N50W. As dolinas dos pontos 124 e 125 e dos pontos 121, 122 e 123 são conjuntos de dolinas menores dentro de depressões maiores, como pode ser visto na Fig. 4A. As dolinas desenvolvem um perfil assimétrico para N190 associadas ao sentido do fluxo de água intermitente (Fig. 4A).

Área da Fazenda Santa Maria $\mathrm{Na}$ área da Fazenda Santa Maria ocorre transição geomorfológica entre arenitos e dolomito subjacente, com a espessura dos arenitos diminuindo de leste para oeste, expondo dolomitos como morros residuais com cavernas (Fig. 3). Em algumas dolinas o dolomito aflora como blocos residuais ou karren no epicarste.

Nesta área as dolinas são tanto amplas e suaves, as mais comuns, quanto mais profundas e escarpadas, menos freqüentes. Fora da área de ocorrência das dolinas, a superfície é praticamente plana, com rugosidade de 1,0003 nas três áreas estudadas (Fig. 3A). Algumas dolinas apresentam morfologia suave nas bordas e abrupta no centro, como no Ponto 28 (Fig. 6). Esta dolina apresenta $\mathrm{P} / \mathrm{D}=0,16$ na dolina como um todo, va-
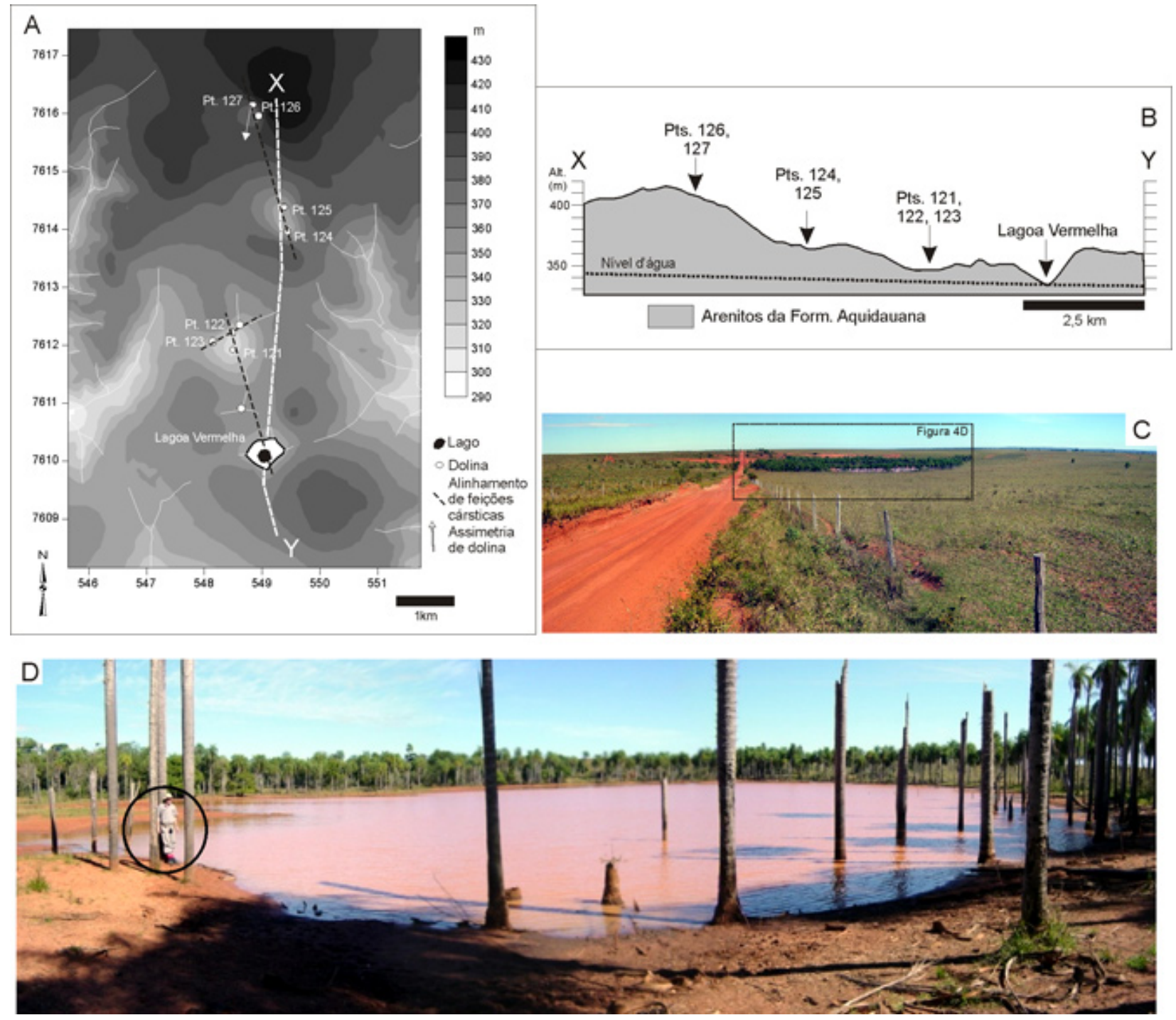

Figura 4 - Dolinas na área da Fazenda Chapéu de Pano. A- Mapa hipsométrico com a localização das dolinas e seus alinhamentos, B-Perfil X-Y da Fig. 4A, C-Vista geral da dolina da Lagoa Vermelha (Ponto 120), D- Detalhe da Fig. 4C (retângulo), com escala (pessoa) indicada com círculo na lateral esquerda. 
riando entre 0,02 na porção mais suave e 1,3 na porção abrupta, onde se forma um colapso em forma de um poço (Fig. 6). O Buraco das Araras, próximo à Fazenda Santa Maria, desenvolvida totalmente no arenito, é um exemplo do tipo menos freqüente de dolina, sendo a mais conhecida da região (Fig. 7). É uma dolina elíptica com paredes escarpadas (verticais), de direção N50W em eixo maior, com 125 e $70 \mathrm{~m}$ de eixos maior e menor, respectivamente, $60 \mathrm{~m}$ de profundidade $(\mathrm{P} / \mathrm{D}=0,64) \mathrm{e}$ lago no fundo da depressão. Nesta dolina as estruturas observadas no arenito por Lino et al. (1984) são fraturas N30-50W/60-70NE e N30-40E/sub-vertical que coincidem com o eixo maior e menor da dolina, além de um acamamento sub-horizontal $\left(5-10^{\circ}\right)$. Outro exemplo deste tipo é a Lagoa Misteriosa é a maior dolina deste tipo com $400 \times 200 \mathrm{~m}$ de eixo maior e menor e 75 $\mathrm{m}$ de profundidade $(\mathrm{P} / \mathrm{D}=0,27)$ e vertentes inclinadas, desenvolvida nos dolomitos, restando apenas um capeamento métrico de arenitos da Formação Aquidauana. Dá acesso a uma caverna subaquática, com desenvolvimento preferencial vertical, de $220 \mathrm{~m}$ de profundidade (Oliveira, 2001 - Figs. 5, 6 e 8).

As feições cársticas encontram-se alinhadas em três direções principais: NS, N45W e N70E (Figs. 5 e 6). O acamamento possui direção N62E/55SE e as fraturas direções N60-75E e N75-90W subverticais. Os alinhamentos com orientação N70E foram relacionados ao sistema de fraturas com atitude N70E/sub-vertical (Figs. 5 e 6). Quando elípticas, as dolinas possuem direções de eixo maior acompanhando as mesmas direções que os alinhamentos N05W-N10E, N35-40E, N70-76E e N40W (Figs. 5 e 6). Esta orientação do eixo maior ocorre nas dolinas da Lagoa Misteriosa (Ponto 28 - Fig. 6) e no Buraco das Araras (Fig. 7). As dolinas desenvolvem um perfil assimétrico para $\mathrm{N}$, associadas ao sentido do fluxo de água intermitente na Fazenda Santa Maria, acompanhando o fluxo das águas superficiais (Figs. 4A e 5).

$\mathrm{Na}$ área da Fazenda Santa Maria são cadastradas sete cavernas na Sociedade Brasileira de Espeleologia

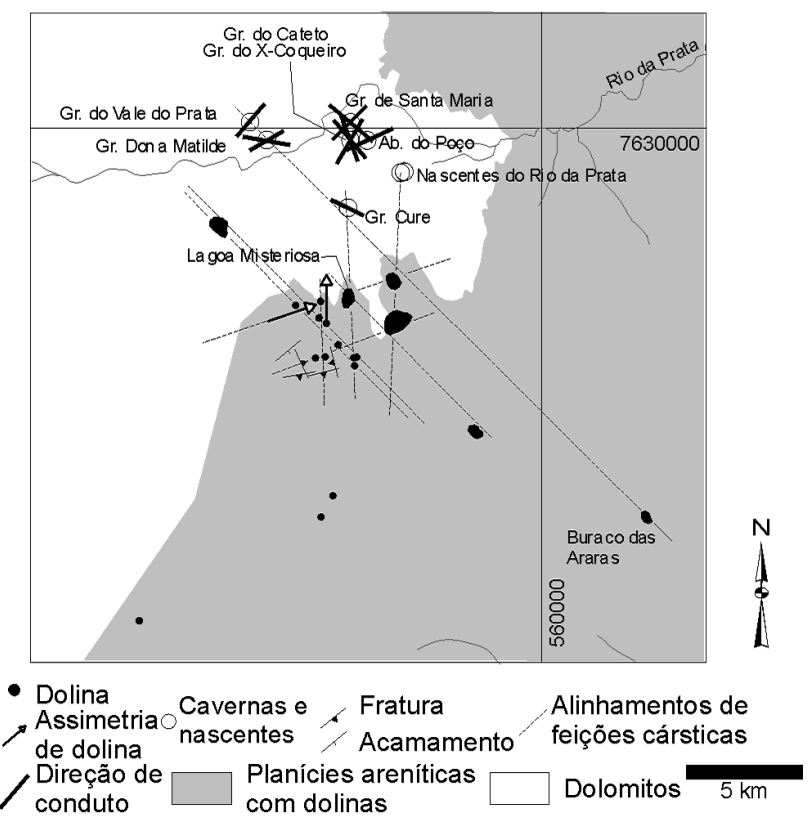

Figura 5 - Mapa de feições cársticas, estruturas e alinhamentos na área da Fazenda Santa Maria.

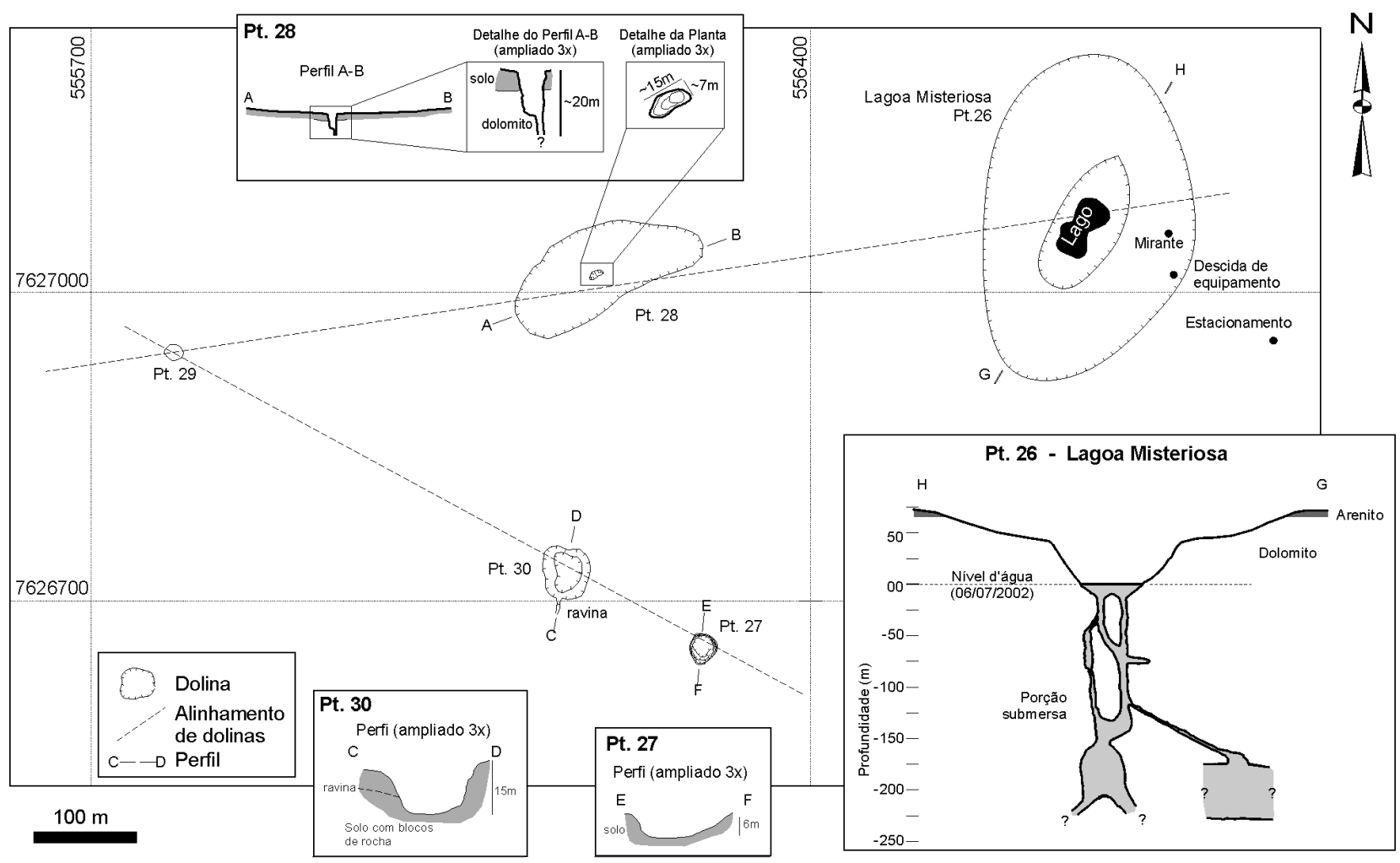

Figura 6 - Representação em planta de algumas dolinas na área da Fazenda Santa Maria. Mapa da Lagoa Misteriosa modificado de Oliveira (2001). 

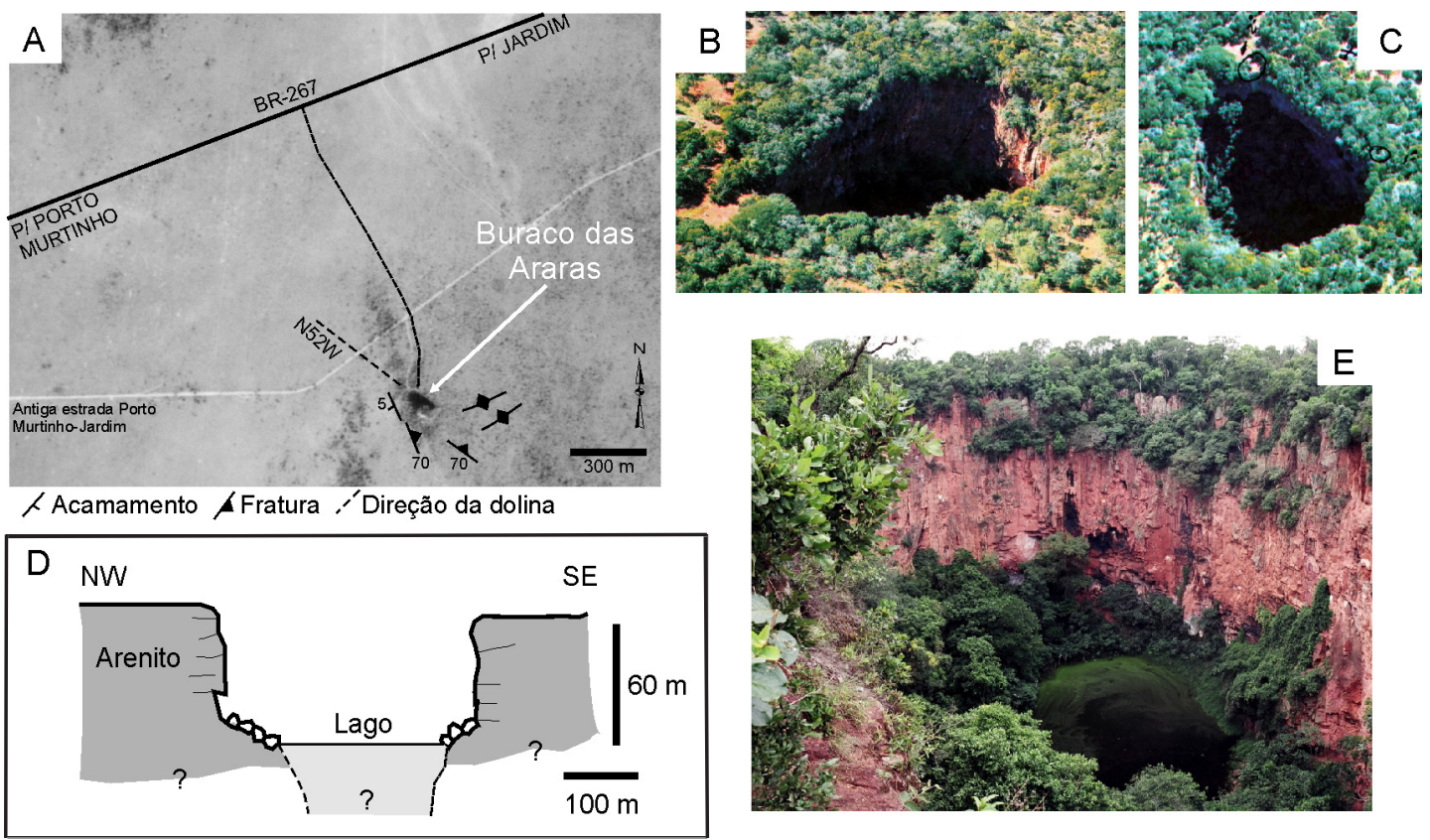

Figura 7 - Buraco das Araras. A- Fotografia aérea em escala 1:60.000 e mapa do contorno, com atitudes de acamamento e fraturas no arenito (modificado de Lino et al. 1984), $B$ e CVista aérea (Fotografias cedidas por Rooswelt R. Sampaio), D-Perfil esquemático (modificado de Lino et al. 1984), E-Vista na direção SE do mirante localizado na borda da dolina.

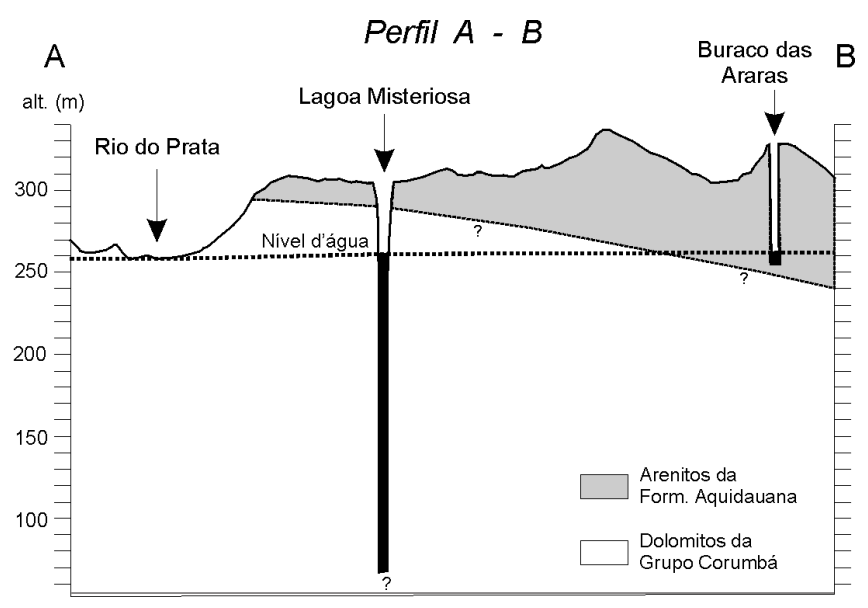

Figura 8 - Perfil na área da Fazenda Santa Maria (perfil $A-B)$, localizado anteriormente na figura 3.
(SBE - Tab. 2). As cavernas constituem salões de abatimento, padrão mais comum nos dolomitos da região, possuindo segmentos de condutos originais segundo direções preferenciais N50W e N65E. Estas direções são compatíveis com os alinhamentos de feições cársticas observadas na região por Sallun Filho (2005). A Gruta do Curê (Fig. 9), por exemplo, exibe este padrão em salão de abatimento e forma geral do conduto original, com direção principal N65W. Nesta caverna também se observa o produto do processo de colapso que gerou a entrada e a clarabóia no seu interior.

DOLINAS NA FORMAÇÃO FURNAS EM PONTA GROSSA (PR) As dolinas em arenitos da região de Ponta Grossa (PR) ocorrem no denominado Segundo Planalto Paranaense (Maack 1968), conhecidas regionalmente como "furnas". Na área estudada, este planalto apresenta altitudes entre 800 e $1150 \mathrm{~m}$, sendo cons-

Tabela 2 - Cavernas da região de Jardim (MS) segundo cadastro da Sociedade Brasileira de Espeleologia (SBE).

\begin{tabular}{l|c|c|c}
\hline No da SBE - Nome & $\begin{array}{c}\text { UTM E / N } \\
(\text { Zona 21K) }\end{array}$ & $\begin{array}{c}\text { Desenvolvimento } \\
(\mathrm{m})\end{array}$ & $\begin{array}{c}\text { Desnível } \\
(\mathrm{m})\end{array}$ \\
\hline MS-15 - Gruta do Curê & $556666 / 7628631$ & 80 & 25 \\
\hline MS-16 - Abismo do Poço & $556994 / 7629792$ & ------ & 20 \\
\hline MS-25 - Gruta de Santa Maria & $556708 / 7630101$ & 253 & 24 \\
\hline MS-26 - Gruta do Cateto & $556707 / 7629793$ & 88 & 5 \\
\hline MS-27 - Gruta do X-Coqueiro & $556707 / 7629793$ & 49 & 13 \\
\hline MS-28 - Gruta do Vale do Prata & $554980 / 7630107$ & 543 & 28 \\
\hline MS-29 - Gruta Dona Matilde & $555267 / 7629798$ & 246 & 46 \\
\hline
\end{tabular}


tituído na área estudada, por rochas sedimentares da Bacia do Paraná, das formações Furnas e Ponta Grossa e do Subgrupo Itararé (Fig. 10). As dolinas se situam junto à escarpa leste do Segundo Planalto, que é deno- minada "Escarpa Devoniana" (Maack 1968), formada pela Formação Furnas, especialmente pela sua unidade inferior por apresentar maior resistência à erosão (Assine 1999). Esta escarpa não possui idade devoniana,

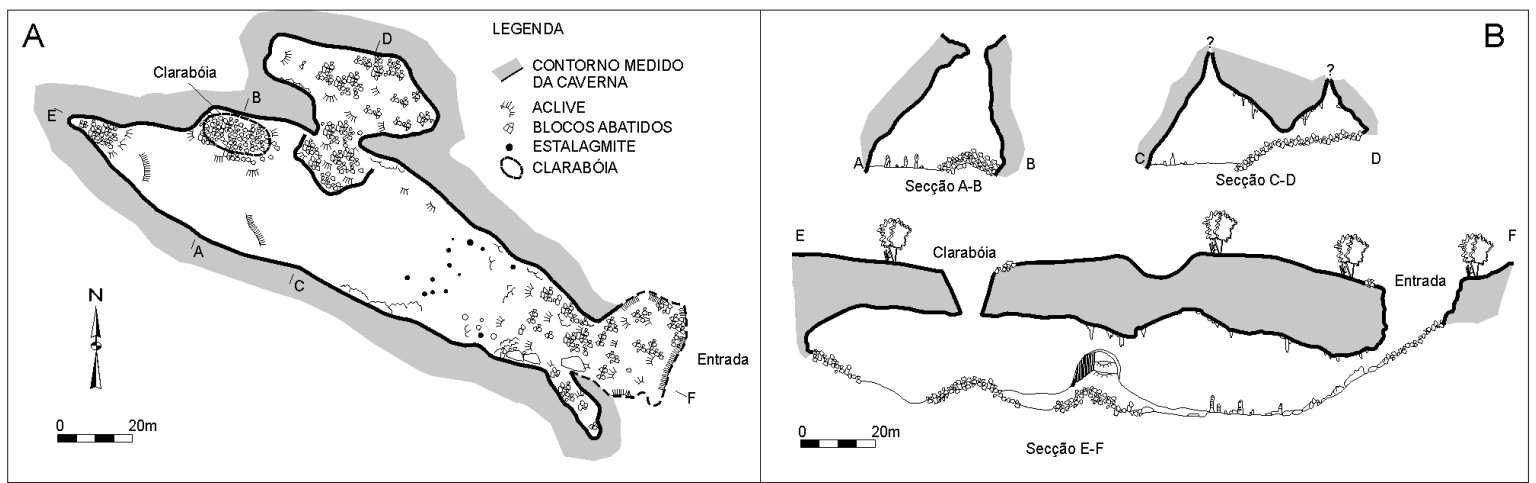

Figura 9 - Planta (A) e perfis (B) da Gruta do Curê (modificado de Lino et al. 1984). Observa-se o padrão em salão de abatimento e a forma ainda preservada do conduto original.
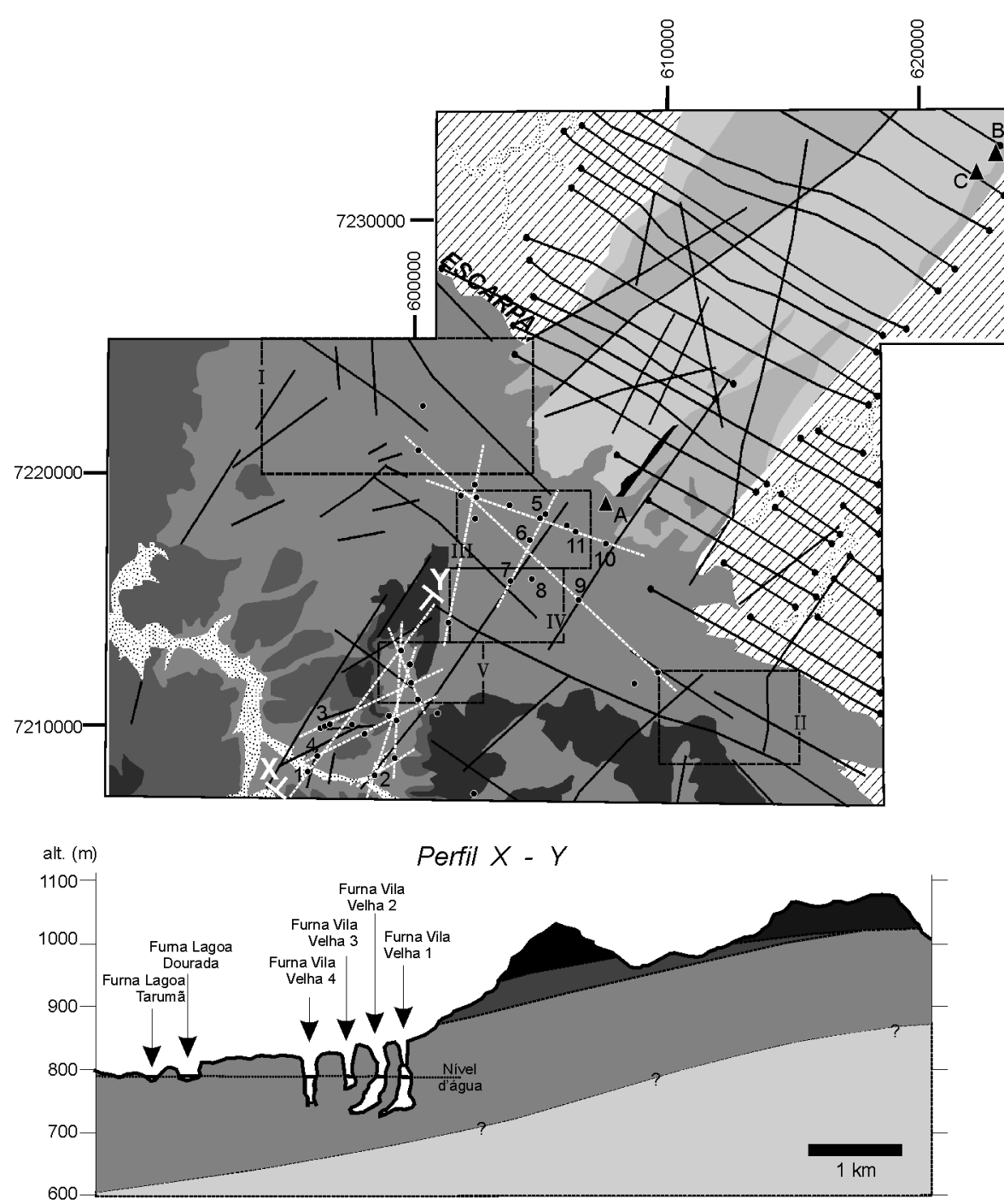

- Dolinas e abismos

1- Furna da Lagoa Dourada

2- Furna da Lagoa Tarumã

3- Furna de Vila Velha I

Furna de Vila Velha II

Furna de Vila Velha III

4- Furna de Vila Velha IV

5- Furna Passo do Pupo I

Furna Passo do Pupo II

6- Furna Buraco Grande

7- Buraco do Padre

8- Abismo do Cercado Grande I

9- Abismo do Cercado Grande II

10- Poço das Andorinhas

11- Furna Abismo do Haras

- Cavernas

Arenito (Formação Furnas)

A- Caverna das Andorinhas

Calcário (Grupo Itaiacoca)

B- Gruta Águas do Inchaço

C- Gruta Olhos D'água

\section{Quaternário \\ $\therefore$ Aluviões \\ Paleozóico \\ Bacia do Paraná \\ - Subgrupo Itararé \\ Formação Ponta \\ Grossa \\ Formação Furnas}

Proterozóico

Grupo Itaiacoca

$\square$ Metadolomitos

Metarenitos, Metarcósesos

Metavzutgânicas

$\square / \triangle$ Granitos

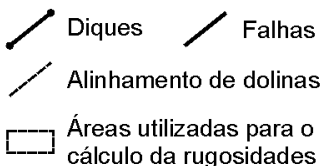

Figura 10 - Mapa geológico e perfil da região de Ponta Grossa (PR), com a de localização de dolinas e cavernas. Mapa geológico modificado de CPRM (1977) e perfil esquemático modificado de Soares (1989). 
mas sim é constituída por arenitos devonianos, como ressaltado por Souza \& Souza (2002), que propõem a utilização do nome de "Escarpamento Estrutural Furnas", também utilizada neste trabalho. A leste da escarpa encontra-se o Primeiro Planalto (Maack 1968), constituído por rochas do embasamento pré-cambriano da Bacia do Paraná, onde se destacam rochas metavulcanossedimentares (incluindo dolomitos) do Grupo Itaiacoca e granitos (Figs. 10 e 11, perfil A-B-C). No Primeiro Planalto as altitudes variam entre 600 e 1000 $\mathrm{m}$, com a paleo-superfície sendo coberta pelos arenitos da Formação Furnas que aumentam de espessura para SW.

A superfície do Segundo Planalto é plana, apresentando rugosidade maior nos pontos onde ocorrem vales e fendas nos arenitos, com índice de rugosidade de 1,006 na escala 1:50.000. Já na área de ocorrência das dolinas o índice de rugosidade é maior do que os índices do Segundo Planalto como um todo, de 1,011 a 1,012 na mesma escala.

Em maior escala, foi observado no MDT, que a área de ocorrência das dolinas está contida dentro de uma grande depressão de expressão morfológica regional. Esta depressão possui $4 \mathrm{~km}$ de largura por $15 \mathrm{~km}$ de comprimento, amplitude altimétrica de até $350 \mathrm{~m}$ (cotas de 800 a 1150 m) e vertentes escarpadas (Fig. 11, perfis D-E e F-G). Esta feição deprimida tem direção N40E e encontra-se alinhada e em continuidade com os dolomitos do Grupo Itaiacoca, ou seja, é a expressão morfológica da subsidência associada á carstificação subjacente (Fig. 11). Esta depressão é denominada neste trabalho de "Depressão de Vila Velha". No Primeiro Planalto os próprios dolomitos encontram-se rebaixados em relação às outras rochas do embasamento, formando também uma depressão (Fig. 11, perfil H-I). Nos mapas de rugosidade e declividade (Fig. 12) observa-se nitidamente a depressão, assim como o relevo cárstico nos dolomitos, que contrastam com relevos indiferenciados mais rugosos e entalhados do Primeiro Planalto e a superfície bastante plana do Segundo Planalto. Notam-se também as bordas escarpadas e mais rugosas da depressão. Na porção onde os arenitos recobrem os dolomitos, a Escarpa da Formação Furnas encontra-se mais retraída, na direção SW (Figs. 10 e 11), menos rugosa e menos escarpada (Fig. 12).

Estão cadastradas 11 dolinas na região de Ponta Grossa (Soares 1989 e cadastro da Sociedade Brasileira de Espeleologia) mas sabe-se da existência de cerca de

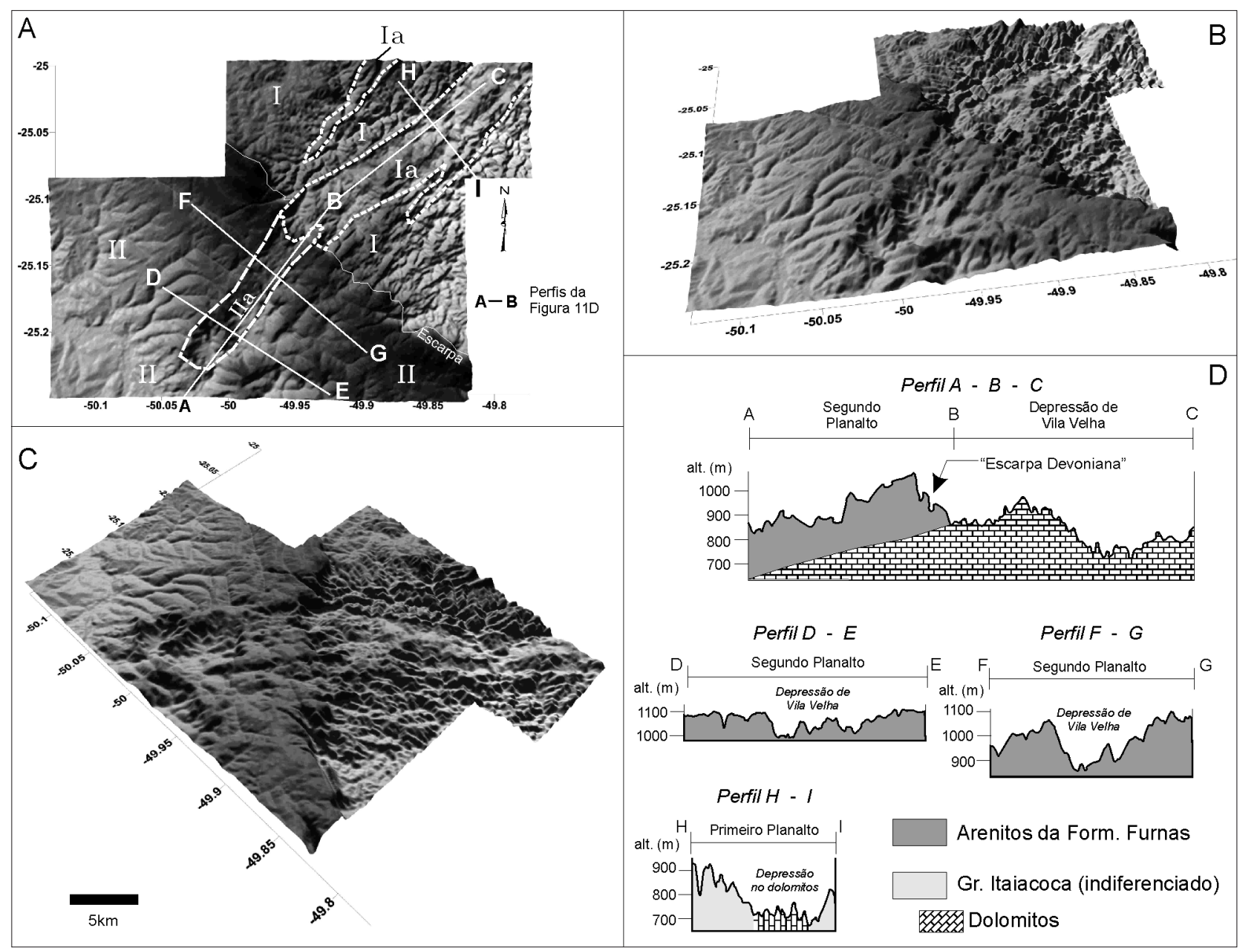

Figura 11 - Modelo digital de terreno (MDT) e principais compartimentos morfológicos (coordenadas em graus decimais): A-Vista superior. I-Primeiro Planalto, Ia-Relevo cárstico (dolomitos do Gr. Itaiacoca); II- Segundo Planalto, IIa-Depressão de Vila Velha (arenitos da Fm. Furnas); B- Vista para N45W; C-Vista para N08E. D-Perfis esquemáticos topográficos, com base no MDT, e geológicos. 

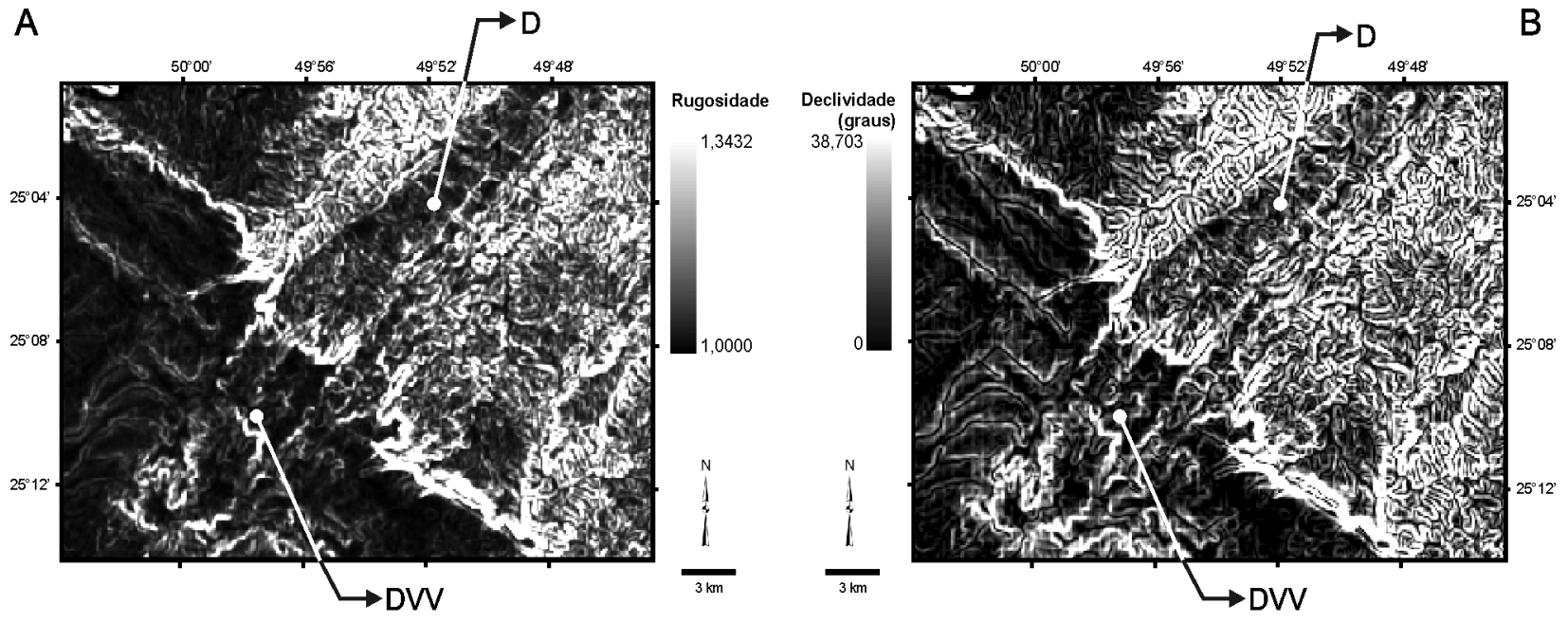

Figura 12 - Mapas de rugosidade $(A)$ e declividade (B) $(D=$ dolomitos e DVV=Depressão de Vila Velha).

Tabela 3 - Dolinas da região das Furnas, Ponta Grossa (PR). Dados obtidos de Soares (1989) e cadastro da Sociedade Brasileira de Espeleologia (SBE).

\begin{tabular}{l|c|c|c|c|c}
\hline $\mathrm{N}^{\circ} \mathrm{SBE}-\mathrm{N}$ ome & $\begin{array}{c}\text { UTM E / N } \\
(\text { Zona } 22 \mathrm{~J})\end{array}$ & $\begin{array}{c}\text { Dimensões em } \\
\text { planta }(\mathrm{m})\end{array}$ & $\begin{array}{c}\text { Prof. } \\
(\mathrm{m})\end{array}$ & Litol.** & P/D \\
\hline PR-1 - Furna de Vila Velha I & $596671 / 7209783$ & 50 & $60\left(+53^{*}\right)$ & Aren. & 2,26 \\
\hline PR-2 - Furna de Vila Velha II & $596531 / 7209753$ & 100 & $54\left(+56^{*}\right)$ & Aren. & 1,1 \\
\hline PR-34 - Buraco do Padre & $603796 / 7215698$ & 40 & 43 & Aren. & 1,07 \\
\hline PR-35 - Furna Passo do Pupo I & $605050 / 7218519$ & 100 & 50 & Aren. & 0,5 \\
\hline PR-36 - Furna Passo do Pupo II & $604881 / 7218489$ & 100 & 53 & Aren. & 0,53 \\
\hline PR-37 - Furna Buraco Grande & $604595 / 7217599$ & 400 & 72 & Aren. & 0,18 \\
\hline PR-38 - Poço das Andorinhas & $607587 / 7217176$ & 70 & 48 & Aren. & 0,68 \\
\hline PR-41 - Furna de Vila Velha III & $596390 / 7209692$ & 100 & 20 & Aren. & 0,2 \\
\hline PR-42 - Furna de Vila Velha IV & $596075 / 7208556$ & 21 & $30(+14 *)$ & Aren. & 2,09 \\
\hline PR-43 - Furna da Lagoa Dourada & $594978 / 7207764$ & 200 & 5 & Aren. & 0,02 \\
\hline PR-44 - Furna da Lagoa Tarumã & $597913 / 7207374$ & 100 & 6 & Aren. & 0,06 \\
\hline
\end{tabular}

*subaquática; **Aren.: Arenito (Form. Furnas).

30 (Melo 2002 - Fig. 10). Possuem diâmetros e profundidades muito variados, atingindo o máximo de $400 \mathrm{~m}$ e $113 \mathrm{~m}$, respectivamente considerando a porção subaquática (Tab. 3).

Da mesma forma que em Jardim (MS), são evidentes dois tipos morfológicos de dolinas, distintos pela morfologia de depressões com vertentes suaves a abruptas, com $\mathrm{P} / \mathrm{D}$ entre 0,02 a 2,26. Porém na região de Ponta Grossa (PR) a morfologia dominante corresponde a dolinas com uma relação $\mathrm{P} / \mathrm{D}$ média a alta (média de 0,79 ), devido à maior profundidade em relação ao diâmetro, e vertentes de inclinação abrupta com forma de "poços". Os melhores exemplos deste tipo de dolinas são as Furnas I, II e IV (Fig. 10) e o Buraco do Padre, que possuem forma de vertentes abruptas e alta profundidade, algumas atingindo o nível d'água. Outras dolinas apresentam morfologia ampla e rasa, com vertentes suaves, como a Lagoa Dourada e a Lagoa Tarumã (Fig. 10).
As dolinas encontram-se alinhadas na direção principal N20-30E, além de algumas ocorrências de direção NW-SE (Fig. 10). Estes alinhamentos são relacionados a fraturas nos arenitos que condicionam as dolinas (Maack 1956, Melo 2002), delimitadas nos mapas geológicos existentes (CPRM 1977 - Fig. 10) como fraturas ou falhas. Estes alinhamentos fazem parte das estruturas do Grupo Itaiacoca, que possui direções gerais de falhas, acamamento e foliação NE-SW, que por sua vez condicionariam também os condutos cársticos em profundidade. A própria Depressão de Vila Velha, descrita acima, também apresenta direção NE, acompanhando nitidamente a direção estrutural dos dolomitos do Grupo Itaiacoca e das grandes falhas, como o lineamento Itapirapuã. As fraturas e falhas de direção NW-SE são relacionadas à formação do Arco de Ponta Grossa, como sugere Melo et al. (2000).

Poucas cavernas cársticas são conhecidas nos dolomitos do Grupo Itaiacoca, tanto no Estado de São 
Tabela 4 - Cavernas da região de Abapã (PR). Dados do cadastro da Sociedade Brasileira de Espeleologia (SBE).

\begin{tabular}{l|c|c|c}
\hline No SBE - Nome & UTM E / N (Zona 22J) & $\begin{array}{c}\text { Desenvolvimento } \\
(\mathrm{m})\end{array}$ & $\begin{array}{c}\text { Desnível } \\
(\mathrm{m})\end{array}$ \\
\hline PR-50 - Gruta Olhos D’água & $622307 / 7231850$ & 500 & ------ \\
\hline $\begin{array}{l}\text { PR-51 - Gruta Águas do } \\
\text { Inchaço }\end{array}$ & $623127 / 7232611$ & 300 & ----- \\
\hline
\end{tabular}

Paulo quanto no Paraná. As cavernas cadstradas mais próximas da região de Ponta Grossa nos dolomitos do Grupo Itaiacoca são duas a cerca de $20 \mathrm{~km}$ a NE da escarpa (PR - Fig. 10), constituindo cavernas relativamente extensas para o padrão regional (Tab. 4). A Gruta Olhos d'Água (GUPE 1992) (Fig. 13) apresenta um padrão de caverna meandrante com presença de rio subterrâneo. Esta caverna mostra alinhamento geral na direção NW-SE, e condutos nas direções N10-30E, N50-60E e N60-80W.

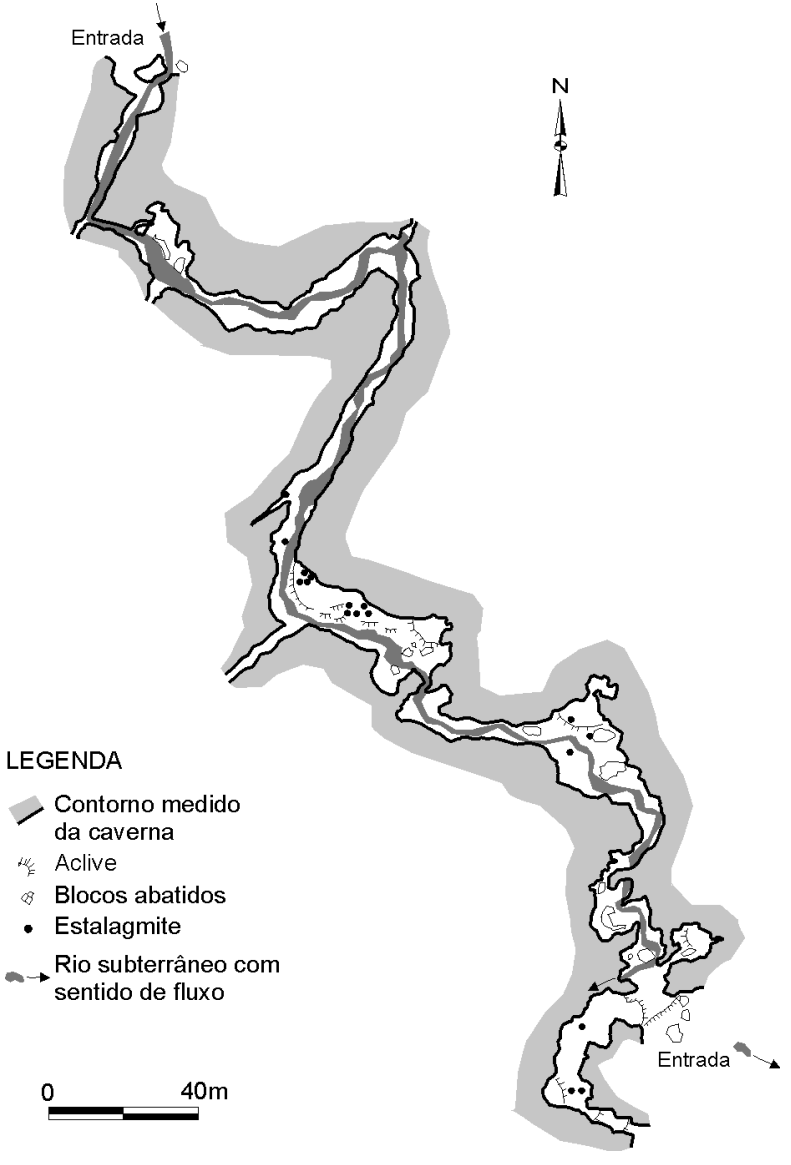

Figura 13 - Mapa da Gruta Olhos d'Água (modificado de GUPE 1992).

DISCUSSÕES As dolinas em arenitos da Bacia do Paraná nas regiões de Jardim (MS) e Ponta Grossa (PR) apresentam semelhanças e diferenças quanto a sua morfologia. Nas duas regiões a alta freqüência de dolinas permitiria classificá-las como um "carste dominado por dolinas" (doline karst, White 1988), porém como se trata de um carste subjacente preferiu-se não adotar este termo. Porém constituem "campos de dolinas", pois são áreas onde ocorre uma alta densidade de dolinas (Jennings 1985). Nas duas localidades as dolinas estão associadas ao recuo por erosão de unidades areníticas, que expõe o embasamento da Bacia do Paraná. Na região de Ponta Grossa este recuo é marcado pela Escarpa da Formação Furnas, enquanto na região de Jardim não existe uma escarpa associada. Observou-se que nas dolinas de Jardim a relação P/D é no geral mais baixa (média de 0,2) do que nas de Ponta Grossa (média de 0,8 ), onde há maior quantidade de dolinas profundas e escarpadas. Em Jardim, há P/D mais baixa na área da Fazenda Chapéu de Pano em comparação com da Fazenda Santa Maria. Dolinas amplas e rasas são associadas à subsidência lenta, enquanto dolinas profundas e escarpadas indicam colapso. Como o caso da dolina Lagoa Dourada (PR), cuja datação dos sedimentos que a preenchem indicam origem por subsidência lenta, de cerca de $1 \mathrm{~mm} /$ ano (Melo et al. 2000).

A interpretação da origem das dolinas da região de Ponta Grossa como devida "apenas" à erosão subterrânea dos arenitos, pela inexistência ou o desconhecimento de rochas carbonáticas subjacentes à Formação Furnas (Maack 1968, Soares 1989, Melo 2002), é totalmente equivocada. Primeiramente, desde trabalhos pioneiros se conhece a existência de rochas carbonáticas no embasamento exposto (Maack 1947) e, da mesma forma, a possibilidade de sua ocorrência sob a Bacia do Paraná. Mesmo nos mapas geológicos antigos (Maack 1953) os corpos carbonáticos estão delimitados, porém com expressão menor do que se conhece atualmente. O Grupo Itaiacoca, que aflora por cerca de $200 \mathrm{~km}$ na direção NE-SW (Fig. 10), certamente possui continuidade sob a Bacia do Paraná por mais alguns quilômetros. Soares (1989) descreve a inexistência de rochas carbonáticas abaixo das dolinas, através de dados de poços perfurados "a poucos quilômetros a NW das ocorrências de Vila Velha". Porém esses poços perfurados ocorrem nas cidades de Ponta Grossa e Carambeí (PR), que se situam a 15 e $22 \mathrm{~km}$ da faixa de ocorrência de dolomitos subjacentes, sendo esperada a ocorrência de outras rochas nestes locais (Fig. 10). Em toda a extensão aflorante das formações Furnas e Aquidauana só são descritas dolinas onde rochas carbonáticas podem ser interpretadas como embasamento abaixo dos arenitos da Bacia do Paraná em Jardim (MS) e Ponta Grossa (PR).

Outro argumento utilizado na região de Ponta Grossa por alguns autores para suportar a idéia da ero- 
são subterrânea dos arenitos como formador de dolinas, é a presença de feições ruiniformes pseudocársticas de superfície. As feições ruiniformes ocorrem na região de Vila Velha (PR) juntamente com as dolinas, porém em arenitos do Subgrupo Itararé (Ab'Saber 1977). São feições superficiais de origem intempérica (arenização) e erosiva do arenito e podem ser atribuídas a pseudocarste (Maack 1956, Bigarella et al. 1994, Melo 2002). Porém esta interpretação de pseudocarste é estendida para as dolinas por estes autores. Entende-se como pseudocarste o terreno com características similares ao carste desenvolvido em rochas não solúveis, formado por processos diferentes da dissolução (Jennings 1971, Ford \& Williams 1989). As dolinas de Ponta Grossa (PR) não são formas de pseudocarste, pois são formas relacionadas à geração de um aqüífero cárstico em carbonatos subjacentes, ou seja, pode-se considerálas integrantes de sistemas cársticos subjacentes. As dolinas podem ocorrer independentemente de feições ruiniformes de pseudocarste, como é o caso de Jardim (MS), bem como o inverso também é possível. As feições ruiniformes de Vila Velha são típicas de pseudocarste, como citado acima, e como são formas superficiais devem ser tratadas separadamente das dolinas. As dolinas poderiam ser atribuídas a pseudocarste se sua origem fosse meramente por processo de carregamento de grãos (tubificação ou piping). Mesmo as formas de pseudocarste em arenitos, são consideradas por alguns autores (Wray, 1997) como carste, devido ao processo de dissolução na arenização que antecede a remoção mecânica dos grãos.

Assim, as dolinas de Jardim (MS) e Ponta Grossa (PR) são fenômenos de colapso e erosão subterrânea nos arenitos, geradas por um processo de piping (lavagem e remoção mecânica de grãos, segundo Ford \& Williams 1989). Para ocorrer o piping é necessária a criação de espaço sob os arenitos, o que só poderia ser feita pelo desenvolvimento de um sistema cárstico profundo, em ambiente freático, nas rochas carbonáticas do embasamento. Isto caracteriza, desta maneira, um carste subjacente, que é aquele que se desenvolve em profundidade através da dissolução de rochas solúveis cobertas por rochas resistentes e insolúveis (Jackson \& Bates 1997, Culver \& White 2005), as quais podem sofrer colapsos e subsidência (com formação de dolinas).

$\mathrm{Na}$ área de Jardim (MS) a relação das dolinas com o carste subjacente é mais visível devido à presença de uma zona de transição, com exposição gradativa dos dolomitos da Formação Aquidauana, pela pequena espessura de arenitos. Neste processo o epicarste e os condutos cársticos são expostos. Já na região de Ponta Grossa não ocorre uma zona de transição, e o carste ocorre somente na área de carste exumado nos dolomitos do Grupo Itaiacoca e não aflora na área encoberta pelos arenitos.

A própria “Depressão de Vila Velha", que abrange as dolinas na região de Ponta Grossa, é um reflexo da remoção de grãos pelo carste subjacente levando todo o terreno à subsidência progressiva. Esta depressão representa a continuidade geomorfológica das áreas re- baixadas formadas pelos dolomitos do Grupo Itaiacoca em relação às outras rochas do embasamento. Na porção onde os dolomitos penetram sob a bacia, a escarpa da Formação Furnas encontra-se recuada, confirmando o papel do carste subjacente na região.

Em ambas as áreas estudadas o gradiente hidráulico conduz a água dos arenitos para os dolomitos, condicionando infiltração difusa através da porosidade intergranular dos arenitos. Isto ocorre especialmente na área de Ponta Grossa visto que o gradiente é maior. Inicialmente o arenito possui maior permeabilidade, por onde flui a maior parte da água (Palmer 1991). Neste estágio, todas as descontinuidades nos carbonatos recebem água na mesma proporção, mas com o passar do tempo algumas fraturas se alargam com a carstificação, até que alguns setores dos carbonatos adquirirem maior permeabilidade e menor resistência, por onde então, concentram-se fluxos da água subterrânea (Palmer 1991).

O alargamento das fraturas e o desenvolvimento de condutos em profundidade nos dolomitos faz com que parte dos grãos de arenitos sejam carregados mecanicamente para dentro do aqüífero cárstico. Isto progressivamente gera vazios que crescem de maneira ascendente nos arenitos, formando dolinas de colapso, e até pontos de injeção na superfície. Com a evolução do processo de subsidência, iniciado e mantido pelo sistema cárstico, os arenitos podem desenvolver porosidade secundária, acentuando a erosão subterrânea nos arenitos.

Assim, as dolinas configuram pontos de injeção de água sendo improvável que algumas dolinas da região de Ponta Grossa, como a Lagoa Dourada, atuem como nascentes de águas profundas, conforme aventado por Melo (2002). Este autor utilizou algumas características da lagoa como critério para esta interpretação, tais como: águas límpidas e minerais pesados que viriam do embasamento a $300 \mathrm{~m}$ de profundidade em águas ascendentes. A hipótese de que a lagoa seja uma nascente devido a águas límpidas é possível, mas não de águas de circulação profunda, vistos que: a) os minerais pesados que, segundo Melo (2002) seriam trazidos diretamente do embasamento, estão presentes na própria Formação Furnas (Suguio et al. 1974), que forma o substrato e as bordas da lagoa; b) o gradiente hidráulico regional é em direção aos dolomitos do Grupo Itaiacoca, visto que os arenitos estão topograficamente elevados, ou seja, a água não ascenderia $300 \mathrm{~m}$ tendo a escarpa como fuga a poucos quilômetros. Maack (1956) descreve inclusive, na mesma região, sumidouros nos arenitos e os relaciona diretamente aos carbonatos.

A ocorrência de dolinas alinhadas, nas duas áreas estudadas, significa que além de acompanharem descontinuidades nos arenitos, representam a expressão dos condutos em profundidade, que por sua vez seguem as mesmas direções. A existência de condutos cársticos é evidenciada pelos alinhamentos de feições cársticas de superfície (Parizek 1976), que mesmo não sendo visíveis se desenvolvem em profundidade, acompanham direções de fraturas e/ou acamamento. Se a premissa da 
iniciação do sistemas cárstico com recarga difusa anda como carste subjacente for correta, as cavernas que ocorrem no carste exposto são uma evidência direta da ocorrência de condutos em subsupefície, uma vez que elas já estiveram recobertas pelos arenitos. Hoje estas cavernas sofrem modificações em ambiente vadoso. $\mathrm{O}$ carste exposto possui feições de relevo cárstico típicas, como depressões, sumidouros, nascentes e cavernas. Porém as feições cársticas não são muito freqüentes ou evidentes, o que é uma característica inerente às rochas dolomíticas das áreas, visto que dolomita é menos solúvel que calcita da mesma forma que os dolomitos em relação aos calcários. Aqüíferos formados nos dolomitos possuem condutos menos freqüentes, porém mais largos, com poucas ou nenhuma forma de superfície (Rauch \& White 1977), bem como em alguns casos dolomitos possuem pouco ou nenhum desenvolvimento de cavernas (Klimchouk \& Ford 2000b). Além disso, colapsos são muitas vezes mais evidentes nos arenitos do que nos próprios calcários e dolomitos, como também observado por Jennings (1971). A Lagoa Misteriosa, na Serra da Bodoquena, é um exemplo notável de quanto profundo o carste pode se desenvolver, mesmo em dolomitos.

CONCLUSÕES A origem das dolinas em arenitos da Bacia do Paraná está relacionada ao processo de piping e colapso nos arenitos decorrente do desenvolvimento de um sistema cárstico em carbonatos subjacentes. O papel do carste subjacente é demonstrado principalmente pelo fato das dolinas não estarem distribuídas ao longo de todas as unidades areníticas da Bacia do Paraná, mas pelo contrário, são restritas apenas em localidades com rochas carbonáticas no embasamento da bacia. Alinhamentos de dolinas, além de demonstrar o controle estrutural nos arenitos, representa a direção de condutos cársticos em subsuperfície nas rochas carbonáticas do embasamento. A "Depressão de Vila Velha", feição geomorfológica que abrange todas as dolinas da região de Ponta Grossa, descrita pela primeira vez neste estudo, está orientada segundo as direções de estruturas e das rochas carbonáticas do embasamento e é reflexo do processo de piping nos arenitos devido ao carste subjacente.

A baixa freqüência ou a ausência de feições cársticas típicas na área de carste exposto se deve à composição dolomítica, e assim muitas vezes as dolinas são mais evidentes nos arenitos do que nos próprios carbonatos. Em Jardim, a transição geomorfológica gradual entre arenitos e carbonatos expõe o carste subjacente, diferentemente da região de Ponta Grossa onde o carste encontra-se distante das dolinas e em maior profundidade.

As feições de relevo ruiniforme que ocorrem na região de Ponta Grossa, são formas superficiais de origem erosiva ou intempérica nos arenitos atribuídas a pseudocarste, e não tem relação direta com as dolinas, que por sua vez mesmo estando na superfície, constituem pontos de injeção de água meteórica, conectados em profundidade ao sistema cárstico.

Agradecimentos À Fapesp pelo financiamento das pesquisas (Proc. $n^{\circ}$ 01/07481-7). Ao Prof. Dr. Luiz Alberto Fernandes (UFPR) pelo empréstimo das fotografias aéreas da região de Ponta Grossa (PR) e a Rooswelt R. Sampaio, do Buraco das Araras, pelo fornecimento de fotografias. Ao mergulhador Gilberto Menezes de Oliveira pelo empréstimo do mapa da Lagoa Misteriosa e a Cláudio Genthner (GEEP Açungui) pelo mapa da Gruta Olhos D'Água.

\section{Referências}

Ab'Saber A.N. 1977. Topografias Ruineformes no Brasil. Geomorfologia, Instituto de Geografia, Universidade de São Paulo, Boletim 50, 14 p.

Alvarenga S.M., Brasil A.E., Del'arco D.M. 1982. Geomorfologia. In: Brasil, Departamento Nacional da Produção Mineral (ed.) Projeto RADAMBRASIL, Folha SF-21 Campo Grande. Rio de Janeiro, MME, n. 28, p. 125184.

Araújo H.J.T., Santos Neto A., Trindade C.A.H., Pinto J.C. A., Montalvão R.M.G., Dourado T.D.C., Palmeira R.C. B., Tassinari C.C.G. 1982. Geologia. In: Brasil, Departamento Nacional da Produção Mineral (ed.) Projeto RADAMBRASIL, Folha SF-21 Campo Grande. Rio de Janeiro, MME, n. 28, p. 9-124.

Assine M.L. 1999. Fácies, icnofósseis, paleocorrentes e sistemas deposicionais da Formação Furnas no flanco sudeste da Bacia do Paraná. Rev. Bras. Geoc., 29(3):357-370.

Beurlen K. 1956. Mapa das escarpas da região entre o Rio Apa e o Rio Negro sul do Estado de Mato Grosso. Escala $1: 63.360$.

Bigarella J. J., Becker R. D., Santos G. F. 1994. Estrutura e origem das paisagens tropicais e subtropicais: fundamentos geológicos-geográficos, alteração química e fisica das rochas e relevo cárstico e dômico. Florianópolis, Editora da UFSC, v. 3, 425 p.

Bizzi L.A., Schobbenhaus C., Gonçalves J.H., Baars F.J., Delgado I. M., Abram M.B., Leão Neto R., Matos G.M.M., Santos J.O.S. 2001. Geologia, tectônica e recursos minerais do Brasil: Sistema de Informações Geográficas - SIG e mapas na escala 1:2.500.000. Brasília, CPRM, 4 CD-ROM.

CPRM 1977. Mapas geológicos das folhas Campo Largo, Ponta Grossa e Palmeira. Projeto Leste do Paraná. São Paulo, Companhia de Pesquisa de Recursos Minerais, DNPM-CPRM-BADEP-UFPR.

Culver D.C. \& White W.B. 2005. Encyclopedia of caves. Burlington, Elsevier/Academic Press, 654 p.

Ford D. \& Williams P. 1989. Karst Geomorphology and Hydrology. London, Chapman \& Hall, $601 \mathrm{p}$.

GUPE 1992. Mapa da Gruta Olhos d'Água (PR-050), Castro-PR. Grupo Universitário de Pesquisas Espeleológicas, Curitiba. Inédito. 
Hiruma S.T., Ferrari J.A., Amaral R. 2007. Geomorfologia cárstica da Faixa Itaiacoca nas regiões de Nova Campina e Bom Sucesso de Itararé. In: Redespeleo, Encontro Bras. de Estudos do Carste, 2, São Paulo, Resumos, p. 16-20.

Hobson R.D. 1972. Surface roughness in topography: quantitative approach. In: R.J. Chorley (ed.) Spatial analysis in geomorphology. New York, USA, Harper \& Row, p. 222-245.

Jackson J.A. \& Bates R.L. 1997. Glossary of Geology. Alexandria, American Geological Institute, 769 p.

Jenness J. 2002. Surface Areas and Ratios from Elevation Grid (surfgrids.avx) extension for ArcView 3.x, v. 1.2. Jenness Enterprises. Disponível em http://www.jennessent.com/arcview/surface_areas.htm. Acessado em 08 de junho de 2006.

Jennings J.N. 1971. Karst: An introduction to systematic geomorphology. London, M.I.T. Press, $252 \mathrm{p}$.

Jennings J.N. 1985. Karst Geomorphology. New York, Basil Blackwell Inc., 293 p.

Klimchouk A. \& Ford D.C. 2000a. Types of karst and evolution of hydrogeologic setting. In: A. Klimchouk, D.C. Ford, A.N. Palmer, W. Dreybrodt (eds.) Speleogenesis evolution of karst aquifer. National Speleological Society, p. 45-53.

Klimchouk A. \& Ford D.C., 2000b. Lithologic and structural controls of dissolutional cave development. In: A. Klimchouk, D.C. Ford, A.N. Palmer, W. Dreybrodt (eds.) Speleogenesis: evolution of karst aquifers. National Speleological Society, p. 54-64.

Le Bret M. 1962. As furnas de Vila Velha - Paraná - Um caso de desmoronamento kárstico no arenito. Tradução de Guy Christian Collet em 1974. Relatório Interno da Sociedade Brasileira de Espeleologia, 6 p.

Lima L.S., Michaele F., Soares O. 1975. Biografia de Vila Velha. Edição do autor, Ponta Grossa, 137 p.

Lino C. F., Boggiani P. C., Cortesão J., Godoy N. M., Karmann I. 1984. Projeto Grutas de Bonito (MS) - Diretrizes para um Plano de Manejo Turístico. Relatório apresentado à MS-TUR, SPHAN e FNPM, São Paulo, 212 p.

Maack R. 1946. Geologia e geografia da região de Vila Velha Estado do Paraná e considerações sobre a glaciação carbonífera no Brasil. Arquivos do Museu Paranaense, vol. V, 305 p.

Maack R. 1947. Breves Notícias Sobre a Geologia dos Estados do Paraná e Santa Catarina Arq. Biol. Tecnol., 2:63154.

Maack R. 1953. Mapa geológico do Estado do Paraná. CCCP, Edição da comemoração do centenário do Paraná, escala 1:750.000.

Maack R. 1956. Fenômenos carstiformes de natureza climática e estrutural nas regiões de arenitos do Estado do Paraná. Arq. Biol. Tecnol., 11:151-162.

Maack R. 1968. Geografia física do Estado do Paraná. Curitiba, IBPT, $350 \mathrm{p}$.

Melo M.S. 2002. Lagoa Dourada, PR. Furna assoreada do Parque Estadual de Vila Velha. In: C. Schobbenhaus, D.A. Campos, E.T. Queiroz, M.Winge, M. Berbert-Born (eds.) Sítios Geológicos e Paleontológicos do Brasil.
Brasília-DF, DNPM, p. 249-259.

Melo M.S., Giannini P.C.F., Pessenda L.C.R. 2000. Gênese e evolução da Lagoa Dourada, Ponta Grossa, Paraná. Rev. Inst. Geol., 21(1/2):17-31.

Milani E.J. \& Ramos V.A. 1998. Orogenias paleozóicas no domínio sul-ocidental do Gondwana e os ciclos de subsidência da Bacia do Paraná. Rev. Bras. Geoc., 28(4):473484.

Oliveira G.M. 2001. Lagoa Misteriosa. In: A. Auler, E. Rubioli, R. Brandi (eds.) As grandes cavernas do Brasil. Belo Horizonte, Grupo Bambuí de Pesquisas Espeleológicas, p. 190-191.

Palmer A.N. 1991. Origin and morphology of limestone caves. Geol. Soc. Am. Bull., 103:1-21.

Parizek R.R. 1976. On the nature and significance of fracture traces and lineaments in carbonate and other terranes. In: V. Yevjevuch (ed.) Karst hydrology and water resources. Colorado, USA, Water Research Publicatons, p. 47-62.

Ponçano W. L., Carneiro C. D. R., Bistrichi C. A., Almeida F. F. M., Prandini F. L. 1981. Mapa geomorfológico do Estado de São Paulo. São Paulo, Instituto de Pesquisas Tecnológicas, 2 v. (Série monografia 5).

Rauch H.W. \& White W.B. 1977. Dissolution kinetics of carbonate rocks. 1. Effects of lithology on dissolution rate. Water Resour. Res., 13:381-394.

Sallun Filho W. 2005. Geomorfologia e geoespeleologia do carste da Serra da Bodoquena, MS. São Paulo, Tese de Doutoramento, Instituto de Geociências, Universidade de São Paulo, 196 p.

Sallun Filho W., Karmann I., Boggiani P.C. 2004. Paisagens cársticas da Serra da Bodoquena (MS). In: V. Mantesso Neto, A. Bartorelli, C.D.R. Carneiro, B.B. Brito Neves (eds.) Geologia do Continente Sul-Americano: Evolução da Obra de Fernando Flávio Marques de Almeida. São Paulo, Beca. p. 424-433.

Santoro E. \& Frascá M.H.B. O. 1989. A Formação Itaiacoca na região de Itapeva, SP. In: SBG, Simp. Geol. Sudeste, 1, Rio de Janeiro, Resumos, p. 99-100.

Soares O. 1989. Furnas nos Campos Gerais, Paraná. Curitiba, Scientia et Labor, $82 \mathrm{p}$.

Souza C.R.G. \& Souza A.P. 2002. O Escarpamento Estrutural Furnas, SP/PR - Raro sítio geomorfológico brasileiro. In: C. Schobbenhaus, D.A.Campos, E.T. Queiroz, M. Winge, M. Berbert-Born (eds.) Sitios Geológicos e Paleontológicos do Brasil. Brasília-DF, DNPM, p. 299-306.

SRTM 2006. Shuttle Radar Topographic Mission. Disponível em http://strm.usgs.gov. Acessado em 19 de junho de 2006.

Suguio K., Coimbra A.M., Guardado L.R. 1974. Correlação sedimentológica de arenitos da Bacia do Paraná. Bol. IGUSP: Série Cientifica, 5:85-116.

White W.B. 1988. Geomorphology and hydrology of karst terrains. New York, Oxford University Press, 464 p.

Wray R.A.L. 1997. Quartzite dissolution: karst or pseudokarst? Cave and Karst Science, 24(2):81-86.

Manuscrito AE 066/2006

Submetido em 08 de dezembro de 2006 Aceito em 15 de setembro de 2007 